\title{
$\cdot \dot{\nabla}$ \\ IJCRR \\ Section: Healthcare \\ Sci. Journal Impact \\ Factor: 5.385 (2017) \\ ICV: 71.54 (2015) \\ In vivo study of Depigmentation Using Tyrosine Ammonia Lyase from Trigonella Foenum-graecum on Zebra Fish Embryos
}

\author{
Kavitha G. Singh'; ${ }^{1}$ Umme Umaima S. ${ }^{2}$; Khushbu Jangid ${ }^{3}$
}

${ }^{1,2,3}$ Department of Biochemistry, Mount Carmel college, Autonomous Palace road, Bangalore.

\section{ABSTRACT}

Aim: To extract Tyrosine ammonia Lyase(TAL) from Trigonella foenum-graecum and utilize it for the treatment of depigmentation by carrying out in-vivo analyses on Zebra fish embryos

Tyrosine ammonia Lyase is an enzyme that is involved in deamination of L-tyrosine to P-coumaric acid. The enzyme TAL was extracted from Trigonella foenum-graecum. This enzyme has been targeted to be used in depigmentation of the skin in the current study using zebra fish as a model organism. This enzyme participates in depigmentation by inhibiting the production of melanin pigment, where in conversion of L-tyrosine in the melamine synthesizing pathway has been prevented by deaminating L-tyrosine to P-coumaric acid. The methodology of separation of proteins using acetone has been implemented in the extraction of the enzyme. Standardization of enzyme was accomplished to detect the presence of the enzyme. The formation of P-coumaric acid indicated the presence of the enzyme that was detected utilizing UV-Visible spectrophotometer at 380nm. In-vivo experimental study was carried on the zebra fish embryos for detecting the presence of the enzyme that was confirmed by observing the depigmented patterns in the developed embryos that were been treated with TAL.

Key Words: L-tyrosine ammonia Lyase, Depigmentation, P-coumaric acid, Trigonella foenum-graceum, Zebra fish

\section{INTRODUCTION}

Depigmentation is a process where the synthesis of melanin pigment is inhibited resulting in de-coloration of skin. The melanocytes losses their ability to synthesize melanin pigment by inhibiting the further conversion of L-tyrosine to participate in the melanin synthesizing pathway, by deaminating L-tyrosine to P-coumaric acid.

The purpose of the current study is to detect the presence of the enzyme tyrosine ammonia Lyase by extracting it from the leaves of Trigonella foenum-graecum, and there by utilizing it to cause depigmentation. The color of the body is induced by melanin pigment that is produced by melanocytes which are present in the lower layer of the epidermis. Tyrosine ammonia Lyase is an enzyme that deaminates L-tyrosine to P-coumaric acid, as a result of which the conversion of L-tyrosine to further products in the pathway is eliminated and the melanin pigment from the melanocytes is not synthesized.
Trigonella foenum-graecum also known as fenugreek plant, belong to the family of Fabaceae, Papillionaceae subfamily. It is an efficient aromatic herb found mostly in Asia and Europe and also in North African areas. It is an ancient plant that is used in treatment of various types of diseases, among which diabetes mellitus is one of them. The leaves of the plant are used as spice in many dishes to improve the taste; the leaves are also known as methi leaves.

Zebra fish is a fresh water living organism found usually in Himalayas and some parts of west Bengal. It belongs to minnow family, It is the most frequently used model organism in most of the research work carried out through conducting in-vivo experiments. The zebra fish genome is fully sequenced and shows $80 \%$ of genomic similarities with that of human genomic sequence and hence has been considered to be most frequently used model organism all over the globe to carry out medicinal research work. The best examples of it are conditions like Parkinson's disorder, alziemer, and atherosclerosis. The embryonic developmental stages have been

\section{Corresponding Author:}

Kavitha G. Singh, Department of Biochemistry, Mount Carmel College, Autonomous Palace Road, Bangalore. Email: kavi182@yahoo.co.in

ISSN: 2231-2196 (Print)

Received: 14.01 .2019
ISSN: 0975-5241 (Online)

Revised: 27.02 .2019
Accepted: 06.04.2019 
well studied and it rapidly develops. The embryos occur to be transparent, with natural pigmentation. It also has the capability to undergo external fertilization.

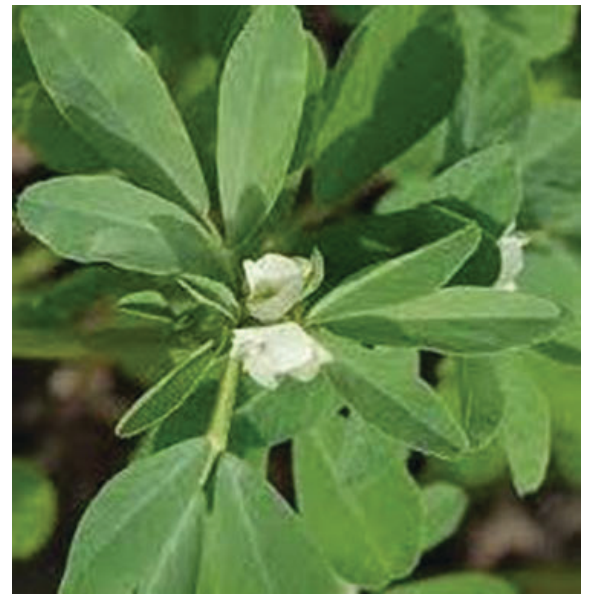

Figure 1: The plant Trigonella foenum-graecum from which TAL was extracted

\section{MATERIALS}

Reagents: Chilled acetone, Chilled distilled water, Tris HCL, HCL (1N), NaOH (1N), L - tyrosine, Methanol.

Instruments: Chilled grinder, Cooling centrifuge, UV spectrophotometer, Computer, Incubator

Refrigerator, $\mathrm{pH}$ Meter.

Other Requirements: Glass wares, Mortar \& pestle, Centrifuge tubes, Muslin cloth, Fresh leaves of Trigonella foenumgraecum.

\section{METHODOLOGY}

\section{Preparation of Tyrosine Ammonia Lyase:}

Trigonella foenum-graecum leaves were collected from north areas of Bangalore. Leaves were washed and air dried to remove water content. $26.6 \mathrm{~g}$ of leaves were weighed and grinded with $100 \mathrm{ml}$ of distilled water using a mixer grinder. The prepared mixture was filtered using muslin cloth. The filtrate was measured; its volume was found to be $110 \mathrm{ml}$ that was refrigerated in freezer for 24 hours. Then to the filtrate equal amount of chilled acetone was added and kept undisturbed in freezer at -20 degree $\mathrm{C}$ for 24 hours. After precipitation two layers were formed, upper layer were discarded and the precipitate containing the protein was collected. Then the precipitate was centrifuged at $5000 \mathrm{rpm}$ for 5 minutes at low temperature in cooling centrifuge. The pallet was collected, washed using acetone and the mixture was then poured into Petri plate for acetone to dry.
The acetone powder obtained was weighed. $1.0 \mathrm{~g}$ of the powder was weighed and homogenized with $20 \mathrm{ml}$ of $1 \mathrm{mM}$ Tris $\mathrm{HCl}(\mathrm{pH}=8.2)$ utilizing a pestle and mortar. The mixture obtained was centrifuged at $5000 \mathrm{rpm}$ for 5 minutes. The crude enzyme extract was obtained in a supernatant form which was used for further analysis. (Umme Umaima et al., 2016) (Sarina P. Khabade, 2014)

\section{Enzyme Assay of Tyrosine Ammonia Lyase:}

Reaction mixture tube was prepared with $1 \mathrm{ml}$ of enzyme source, $0.2 \mathrm{ml}$ of $1 \mathrm{mM}$ L-Tyrosine (substrate) and $0.8 \mathrm{ml}$ of $0.1 \mathrm{M}$ Tris $\mathrm{HCl}$ buffer $(\mathrm{pH}=8.9)$. A control tube was also prepared using $1 \mathrm{ml}$ of distilled water instead of $1 \mathrm{ml}$ of enzyme extract. Both the tubes were incubated in incubator at $37^{\circ} \mathrm{C}$ for 30 minutes. After incubation reaction is terminated by the addition of $0.5 \mathrm{ml}$ of $1 \mathrm{~N} \mathrm{HCl}$. Tyrosine Ammonium Lyase enzyme deaminates L-Tyrosine and produce p-coumaric acid with the release of ammonia. Then it was quantitatively measured by using UV - Visible spectrophotometer at 380nm. (Umme Umaima et al., 2016).

\section{Experiment on Zebra Fish (In-Vivo) To reach depigmentation:}

Zebra fishes were maintained in lab condition and allowed to mate in a breeding tank. Embryos of Zebra fish were collected after 20 hours of fertilization before the pigmentation was produced and were transferred in a Petri plate containing embryo water. Two Petri plates containing zebra fish embryos were taken and marked as control and test. Control plate with the zebra fish embryos was left as such without the addition of enzyme Tyrosine ammonia Lyase, where as test Petri plate with zebra fish embryos was treated with 1 $\mathrm{ml}$ of enzyme extract of Tyrosine Ammonia Lyase. Both the plates containing zebra fish embryos were kept at optimum temperature and observed under microscope after 24 hours of incubation. After observation the embryo water in the petri plate was cleaned and the plates were again added with enzyme Tyrosine Ammonia Lyase. Then the petri plates containing zebra fish embryos were further incubated at optimal temperature and were observed after 24 hours for better result. (Umme Umaima et al., 2016) (Sarina P. Khabade, 2014)

\section{RESULT}

Presence of enzyme Tyrosine Ammonia Lyase was confirmed in Trigonella foenum-graecum. Enzyme was assayed as per the standard conditions. UV-Visible spectrophotometer was used to check the activity of enzyme at $380 \mathrm{~nm}$. When the in-vivo experiment was performed on the zebra fish embryos, showed a gradual decrease in the pigmentation of the test samples induced with particular concentration of enzyme when compare to the control. 
Table 1: Enzyme assay of Tyrosine Ammonia Lyase at $380 \mathrm{~nm}$

\begin{tabular}{ll} 
Trial & OD at $380 \mathrm{~nm}$ \\
Control & 0.010 \\
Test & 0.704 \\
\hline
\end{tabular}

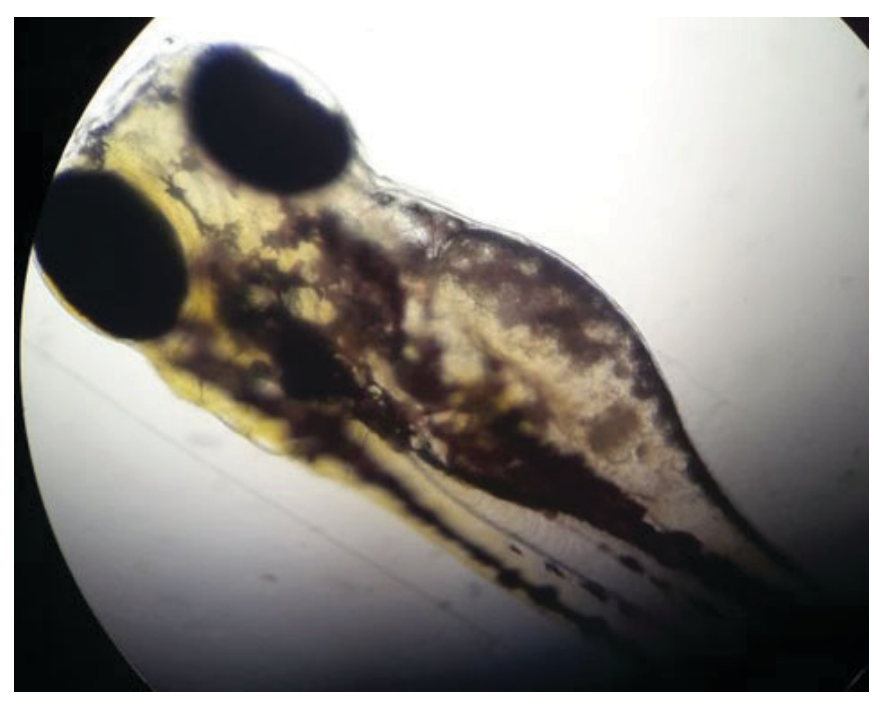

Figure 2: Control: untreated with enzyme (TAL).

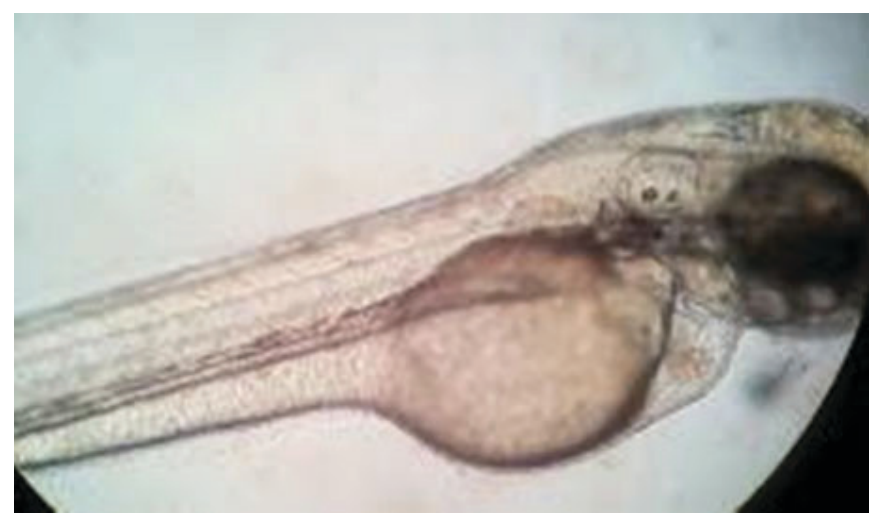

Figure 3: Test: Treated with enzyme (TAL).

\section{DISCUSSION}

The test sample (Trigonella foenum-graecum) in comparison with that of control indicated the presence of

Enzyme tyrosine Ammonia Lyase in a rich amount as a result of conversion of L-Tyrosine to p-coumaric acid by the action of enzyme(TAL). The presence of enzyme in a higher concentration in the sample enables the use of the sample to carry out the depigmentation experiment through carrying out in-vivo study on zebra fish embryos. The clear indication of depigmentation is obtained through observing the above figure 2 and 3.

The above figure 2 and figure 3 that represent the embryos in the control sample (figure 2) that is left untreated with enzyme Tyrosine Ammonia Lyase and the embryos in the test sample ( figure 3) treated with the enzyme Tyrosine Ammonia Lyase. The absence of pigmented stripes in the test sample embryos (figure 3) indicates the identical effect of the enzyme obtained through the sample Trigonellafoenumgraecum which resulted in Depigmentation.

\section{CONCLUSION}

Leaves of Trigonella foenum-graecum are found to contain numerous useful and multi nutritive values, hence is used as herb in many Ayurveda medicines in case of treatment of many diseases, one of them is diabetes mellitus. Depigmentation is characterized as condition where in skin becomes white, as result of inhibition of melanin pigment that is responsible for darkening of skin color. There are many therapeutics and sunscreens creams being used in obtaining the depigmented state, which are useful only for a short period, moreover there are many side effects that get induced affecting the skin and sometimes other parts of the body. As a result of this consequences Trigonella foenum-graecum containing multi nutritive value, medicinal properties along with its zero side effect inducing ability, has been implemented to be utilized inducing depigmentation in the current study and as well as can be utilized in the treatment of many other diseased condition.

\section{ACKNOWLEDGEMENT}

We are thankful to the management and principal of Mount Carmel college for giving us the facility to pursue our research work.

\section{Conflict of interest: None}

\section{REFRENCES}

1. P Khosla, DD Gupta, RK Nagpal. Effect of Trigonella foenum graecum ( Fenugreek) on blood giucose normal and diabetic rats. Indian journal of physiology and pharmacology 39, 173173, 1995.

2. S. Kaviarasan, GH Naik, R Gangabhagirathi, CV Anuradha, KI Priyadarsini. In vitro studies on antiradical and antioxidant activities of fenugreek (Trigonella foenum graecum) seeds. Food chemistry 103(1), 31-37, 2007.

3. K Srinivasan. A review of Health Beneficial Physiological Effect: Fenugreek(Trigonella foenum graceum). Food review international 22(2), 203-224, 2006.

4. Zia Tayyaba, S Nazrul Hasnain, SK Hassan. Evaluation of oral hypoglycemic effect of Trigonella Foenum graceum(Fenugreek) in normal mice. Journal of ethnopharmacology 75(2-3), 191195, 2001.

5. Kowichi Jimbow, Hiroko Obata, Madhu A Pathak, Thomas B Fitzpatrick. Mechanism of De-pigmentation by hydroquinone. Journal of investigation Dermatology 62(4), 436-449, 1974. 
6. Gail K Naughton, Diana Reggiardo, Jean-Claude Bystryn. Correlation between vitiligo antibodies and extent of De- pigmentation in vitiligo. Journal of American Academy of Dermatology 15(5), 978-981, 1986.

7. TP Dooley. Topical skin de- pigmentation agents: current products and discovery of novel inhibitors of melanogenesis, Journal of Dermatological Treatment 8(4), 275-283, 1997.

8. K M AlGhamdi, A Kumar. De-pigmentation therapies for normal skin in vitiligo universalis. Journal of the European Academy of Dermatology and Venereology 25(7), 749-757, 2011.

9. Jens Rosler, Florian Krekel, Nikolaus Amrhein, Jurg Schmid. Maize phenylalanine ammonia-lyase has tyrosine ammonialyase activity. Plant physiology 113(1), 175-179, 1997.

10. M Jason MacDonald, Godwin B D'Cunha. A modern view of phenylalanine ammonia lyase. Biochemistry and Cell Biology 85(3), 273-282, 2007.
11. Robert Gerlai. Zebra fish: an uncharted behavior genetic model Behaviour genetics 33(5), 461-468, 2003.

12. Charles B Kimmel, Jill Patterson, Richard O Kimmel. The development and behavioral Characteristics of the startle response of Zebra fish. Developmental psychobiology 7(1), 47-60, 1974.

13. Charles B Kimmel, William W Ballard, Seth R Kimmel, Bonnie Ullmann, Thomas F Schilling. Stages of embryonic development of the Zebra fish. Developmental dynamics 20393), 253310, 1995.

14. John H Postlethwait, Yi-Lin Yan, Michael Gates, Sally Horne, Angel Amores, Alison. Vertebrates Genome evolution and the zebra fish gene map. Nature genetics 18(4), 345, 1998.

15. Graham J Lieschke, Peter D Currie. Animals models of human disease: zebra fish swim into view, Nature Reviews Genetics 8(5), 353, 2007.

16. LK Cole, LS Ross. Apoptosis in the developing zebra fish embryo. Developmental biology 240(1), 123-142, 2001. 